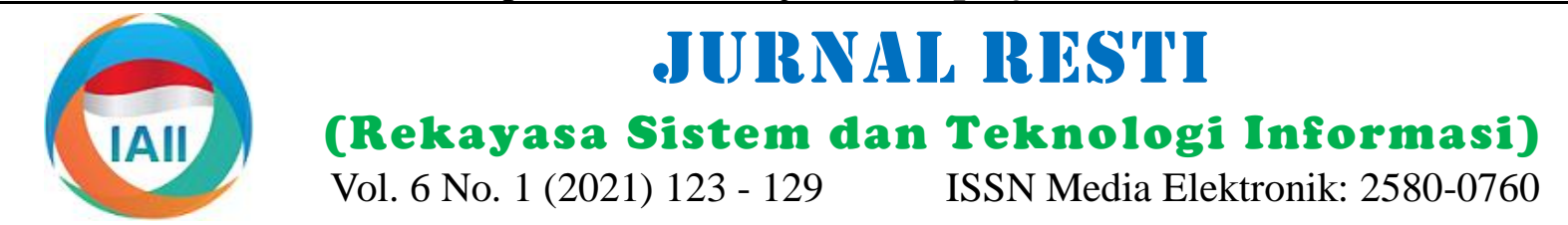

\title{
Perbandingan Model Proses Algoritma Alpha dan Alpha++ Pada Aplikasi E-commerce
}

\author{
Bambang Jokonowo ${ }^{1 *}$, Miskah Alfiyyah Kulsum², Nita Komala ${ }^{3}$, \\ 1,2,3 Sistem Informasi, Fakultas Ilmu Komputer, Universitas Mercu Buana \\ 241818010102@student.mercubuana.ac.id, ${ }^{3} 41818010069 @$ student.mercubuana.ac.id, \\ ${ }^{1}$ Bambang.jokonowo@mercubuana.ac.id*
}

\begin{abstract}
Utilization of information technology is currently growing rapidly in helping activities especially in storing an event log. The activity which is behavior of the user can be analyzed using process mining. The process mining purpose to extract information from event logs on business processes that working. Discovery technique is used in this research. The purpose of this study is to compare two algorithms applied by creating an e-commerce application that is aware of the processes. E-commerce applications require event logs to read the behavior of visitor activities against the application. This research method starts from understanding the business processes that working, then designing a website by creating the application used. Furthermore, data collection through applications that are promoted through social media. The application will be recorded user activity and formed an event log. The event log that formed then discovered using alpha and alpha++ algorithms by utilizing the ProM Lite 1.2 tools. The evaluation results show that the alpha algorithm has shortcomings, namely length one loop, length two loop and non-free choice. And the alpha++ algorithm fixed this deficiency.
\end{abstract}

Keywords: Alpha, Alpha++, Process Discovery, Process mining, Event log, E-commerce

\begin{abstract}
Abstrak
Pemanfaatan teknologi informasi saat ini berkembang sangat pesat dalam membantu aktivitas terutama dalam penyimpanan sebuah event log. Aktivitas tersebut yang merupakan behavior dari user dapat dianalisa menggunakan proses mining. Proses mining bertujuan untuk mengekstrak informasi dari event log pada proses bisnis yang dijalankan. Salah satu teknik proses mining yang digunakan pada penelitian ini yaitu teknik discovery. Tujuan dari penelitian ini adalah membandingkan dua algoritma yang diaplikasikan dengan membuat aplikasi e-commerce yang aware terhadap proses. Aplikasi e-commerce membutuhkan event log untuk membaca perilaku aktivitas pengunjung terhadap aplikasi. Metode penelitian ini dimulai dari pemahaman proses bisnis yang dijalankan, kemudian merancang website dengan membuat aplikasi yang digunakan. Selanjutnya pengumpulan data melalui aplikasi yang dipromosikan melalui media social. Aplikasi akan merekam aktivitas user dan membentuk event log. Event log yang terbentuk kemudian di- discover menggunakan algoritma alpha dan alpha++ dengan memanfaatkan tools ProM Lite 1.2. Hasil evaluasi menunjukan algoritma alpha memiliki kekurangan yaitu length one loop, length two loop dan non-free choice. Dan algoritma alpha++ memperbaiki kekurangan tersebut.
\end{abstract}

Kata kunci: Alpha, Alpha++, Proses Discovery, Proses Mining, Event log, E-commerce

\section{Pendahuluan}

Pemakaian teknologi internet menjadi salah satu hal yang penting dalam dunia bisnis karena menjadi media promosi yang bagus bagi perusahaan dan memberikan kemudahan bagi para calon pelanggan untuk melakukan transaksi pembelian barang [1]. Pada dasarnya layanan web yang dimiliki perusahaan berperan penting dalam upaya pemasaran produk [2]. Banyaknya informasi yang perlu diperbarui setiap saat dalam hubungan bisnis sudah pasti menjadi kunci utama dalam sebuah pemasaran. Proses bisnis dapat dianalisa untuk mendapatkan pengetahuan mengenai aktivitas proses dalam sistem informasi. Proses dapat dimodelkan menggunakan event log yang disimpan [3]. Untuk mendukung proses bisnis, aplikasi perusahaan perlu aware terhadap suatu proses. Proses aware dalam aplikasi adalah sistem perangkat lunak yang mengelola dan menjalankan proses operasional yang melibatkan rang, aplikasi, dan/atau sumber informasi berdasarkan model proses [4].

Diterima Redaksi: 25-12-2021 | Selesai Revisi: 24-02-2022 | Diterbitkan Online: 27-02-2022 
Pemanfaatan teknologi informasi saat ini berkembang yang diusulkan dapat dilihat pada Gambar 1 .

sangat pesat dalam membantu aktivitas terutama dalam penyimpanan sebuah data event [5]. Biasanya data event tersebut akan tersimpan dalam bentuk event log, merupakan proses suatu catatan kejadian yang berisi data urutan suatu peristiwa yang mengacu pada setiap kasus dan aktivitas [6][7]. Log ini bisa dianalisa menggunakan process mining [8] yang merepresentasikan proses bisnis. Oleh karena itu, bila perusahaan atau organisasi telah mempunyai aplikasi yang menyimpan log secara otomatis, maka process mining akan lebih praktis dilakukan [9].

Penelitian yang dilakukan oleh [10] membahas tentang algoritma alpha miner yang menggunakan event log data dari aplikasi pembelajaran online. Dari penelitian tersebut mendapatkan model proses berdasarkan aktivitas pengerjaan kuis. Hasil dari eksperimen menggunakan data real dan dummy penelitian telah dilakukan dan terbukti bahwa implementasi algoritma alpha miner dapat bekerja dengan benar pada data event $\log$ tersebut.

Dalam penerapan process mining [10][11] bahwa event $\log$ perlu beberapa pre-processing sebelum dapat dianalis dengan process mining tool. Pada proses discovery algoritma telah dilakukan pengembangan untuk menemukan beberapa jenis relation [11].

Dalam penelitian ini, permasalahan yang akan diidentifikasi adalah perbandingan antara algoritma alpha dan alpha++ dalam menganalisa sebuah pola pengunjung website pada aplikasi e-commerce. Perilaku bisa diketahui dari aktivitas karena dibuatnya sebuah event $\log$ yang berguna untuk mencatat semua aktivitas yang dilakukan oleh user ke dalam database. Untuk mendukung aplikasi e-commerce ini, akan dicari aspek dari model proses yang didapat. Pencarian ini bisa diawali dengan melihat akses pengguna disitus web, setelah itu dilakukan discovery menggunakan algoritma alpha dan alpha++ untuk mengetahui dan mendeteksi perilaku user terhadap aplikasi.

Pada penelitian ini peneliti menggunakan teknik discovery untuk melakukan process mining. Peneliti memanfaatkan tool ProM untuk melihat sebuah hasil dalam bentuk petri net serta membandingan sebuah model proses pada dataset dengan hasil process mining dengan menggunakan algortima alpha dan alpha++.

Berdasarkan latar belakang di atas, peneliti membuat aplikasi e-commerce yang memperhatikan proses aware guna mendapatkan sebuah event $\log$ untuk dapat dilakukan tahap process mining dalam menganalisa perbandingan menggunakan algoritma alpha dan alpha++ untuk mendapatkan model proses bisnis.

\section{Metode Penelitian}

Dalam metode penelitian ini akan dijelaskan beberapa tahapan melakukan proses mining. Tahapan penelitian

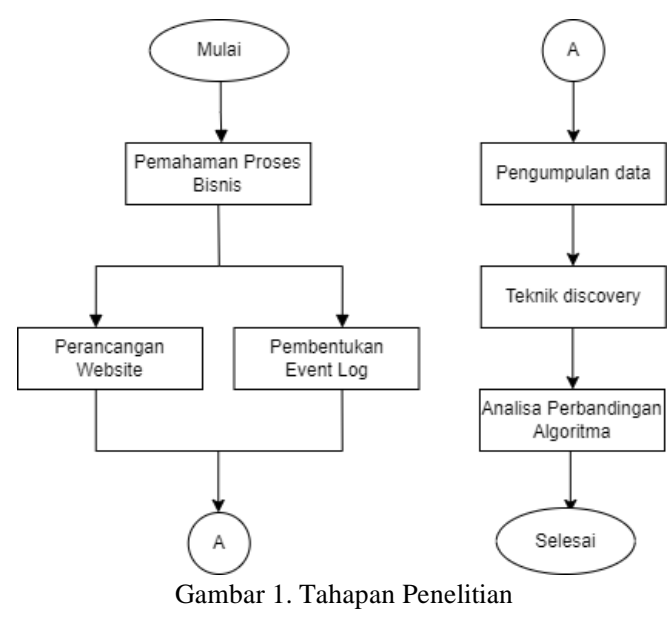

2.1. Pemahaman Proses bisnis

Pada proses ini diperlukan sebuah pemahaman dalam proses bisnis. Hal ini penting untuk memahami sebuah proses bisnis pada penelitian yang berguna mengetahui setiap bagian proses yang dapat dianalisa. Dalam penelitian ini kita dapat melihat aktivitas sebuah user dalam mengunjungi aplikasi e-commerce. Aktivitas tersebut akan diakhiri dengan end event yang berbedabeda. Pada dasarnya setiap user akan memiliki aktivitas yang beragam. Di mana user dapat melakukan sampai tahap transaksi, hanya melihat-lihat product pada aplikasi tersebut dan juga bisa memasukan product ke dalam keranjang tanpa melakukan checkout product terlebih dahulu yang dikarenakan user dalam menggunakan aplikasi e-commerce tidak memiliki Standard Operating Procedure (SOP).

\subsection{Perancangan Website}

Perancangan website ini didasarkan pada kebutuhan dan class diagram yang telah dibuat, sebagai acuan untuk mengetahui struktur dari suatu sistem dengan jelas dan dapat memberikan gambaran mengenai sistem serta relasi. Dari perancangan ini beralih ke pembuatan aplikasi. Aplikasi ini menggunakan Tailwind sebagai framework front-end yang bisa merealisasikan tampilan multi-device sesuai perangkat pengguna. Back-end menggunakan framework laravel karena terdapat library yang cukup banyak di mana dapat mempermudah developer dalam pengembangan sebuah aplikasi dengan Bahasa pemrograman yang digunakan yaitu PHP.

\subsection{Pembentukan Event log}

Event log dibentuk untuk proses aware [12], adalah sebagai konteks dari semua informasi dapat digunakan untuk mendapatkan pemahaman yang lebih dalam tentang situasi dari sebuah event [8]. Dalam pembentukan event log diperlukan sebuah logic dalam codingan agar ketika user melakukan sebuah event akan terekam otomatis dalam database. Aplikasi e-commerce dibuat menggunakan framework laravel. Tiap event 
berisi code yang sama tetapi ada beberapa yang memang pada penambangan proses yang memanfaatkan ditambahkan sesuai kebutuhan.

\subsection{Pengumpulan Data}

Pada proses ini peneliti melakukan hosting aplikasi yang telah dibuat untuk mendapatkan data event log. Pengumpulan data berdasarkan database pada aplikasi e-commerce yang dapat diakses pada link berikut http://niq-interior.my.id/. Pengumpulan data dilakukan dalam periode 9 Oktober 2021 hingga 21 Oktober 2021. Dengan cara mempromosikan melalui media social seperti Instagram dan Whatsapp. Data tersebut berupa kumpulan aktivitas-aktivitas yang dilakukan oleh user pada saat mengakses aplikasi.

Dalam dataset ini terdapat atribut yaitu id, users_id, activity, products_id, category_id, user_session, created_at, updated_at dan ip_address. Selanjutnya dari dataset dilakukan ekstraksi dari hasil export file database event log dalam bentuk format CSV dengan data sebanyak 1380, ringkasan dataset ditunjukan pada Gambar 2.
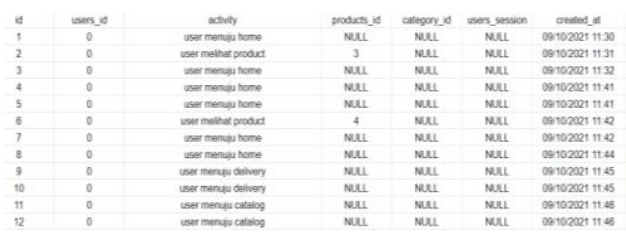

Gambar 2. Ringkasan Dataset aktivitas-aktivitas yang terdapat pada alur kerja untuk dianalisa sehingga membentuk petri net yang menggambarkan proses bisnis yang berhasil dianalisa [14].

Kelebihan dari algoritma alpha ialah kemudahannya untuk dijangkau serta diaplikasikan dalam process mining. Rangkaian eksekusi suatu model proses sebagai input. Catatan ini berasal dari algoritma alpha yang dapat membentuk ringkasan dari susunan serta kaitan dengan peristiwa [15].

Tabel 2. Perbandingan Alpha \& Alpha++

\begin{tabular}{lll}
\hline Algoritma & Kelebihan & Kekurangan \\
\hline Alpha & - & Length one loop \\
& & Length two loop \\
& Invisible task \\
& Duplicate Task \\
& Implicit Task \\
& & Non free Choice \\
\hline Alpha++ & Length one loop & Invisible task \\
& Length two loop & Duplicate Task \\
& Non free Choice & Implicit Task \\
\hline
\end{tabular}

Algoritma didefinisikan dalam istilah petri net. Berikut merupakan proses pada algoritma alpha untuk mendapatkan sebuah Workflow net / Petri net yaitu sebagai berikut [15]:

Membentuk sekelompok transisi di workflow net $\left(T_{L}\right)$

Kemudian setiap aktivitas diberi label untuk mempermudah pengelompokan pada dataset, tujuannya adalah agar model proses yang telah dibuat nampak lebih sederhana dengan menampilkan label tersebut. Yang ditunjukan pada Tabel 1.

Tabel 1. Label Dataset Berdasarkan Activity

\begin{tabular}{ll}
\hline Label & Activity \\
\hline $\mathrm{A}$ & User menuju home \\
$\mathrm{B}$ & User menuju dashboard \\
$\mathrm{C}$ & User menuju catalog \\
$\mathrm{D}$ & User melihat product \\
$\mathrm{E}$ & User melihat daftar keranjang \\
$\mathrm{F}$ & User memasukkan product ke dalam keranjang \\
$\mathrm{G}$ & User menuju delivery \\
$\mathrm{H}$ & User melakukan checkout product \\
$\mathrm{I}$ & User menghapus product \\
\hline
\end{tabular}

\subsection{Teknik Discovery}

Process mining terdiri dari beberapa task, salah satunya adalah proses discovery. Ini adalah metode untuk secara langsung membentuk process bisnis saat ini kemudian mencatat berbagai proses yang terjadi dalam suatu bisnis. Karena process discovery adalah bagian dari teknik process mining, tujuan utamanya adalah untuk menemukan proses model dari log peristiwa yang menggambarkan perilaku terbaik dari proses bisnis yang diimplementasikan dalam suatu bisnis [13].

$T_{L}=\left\{t \in T \mid \exists_{\sigma \in L} t \in \sigma\right\}$

Membentuk transisi source input place pada workflow net $\left(T_{I}\right)$

$T_{I}=\left\{t \in T \mid \exists_{\sigma \in L} t=f \operatorname{first}(\sigma)\right\}$

Membuat transisi output sink place pada workflow net $\left(T_{O}\right)$

$T_{O}=\left\{t \in T \mid \exists_{\sigma \in L} t=\operatorname{last}(\sigma)\right\}$

Algoritma $\alpha$ menentukan transisi mana yang berelasi secara casual

$X_{L}=\left\{(A, B) \mid A \subseteq T_{L} \wedge A \neq \emptyset \wedge B \subseteq T_{L} \wedge B \neq \emptyset \wedge\right.$

$\forall_{a \in A} \forall_{b \in B} a \rightarrow L^{b} \wedge \forall_{a 1, a 2 \in A} a_{1} \# L^{a_{2}} \wedge$

$\left.\forall_{b 1, b 2 \in B} b_{1} \# L^{b_{2}}\right\}$

Menetapkan hasil pasti places yang didapat oleh workflow net

$Y_{L}=\left\{(A, B) \in X_{L} \mid \forall\left(A^{\prime}, B^{\prime}\right) \in X_{L} A \subseteq A^{\prime} \wedge B \subseteq B^{\prime} \Rightarrow\right.$

$\left.(A, B)=\left(A^{\prime}, B^{\prime}\right)\right\}$

Membuat place yang sudah terindikasi sebelumnya

$P_{L}=\left\{P_{(A, B)} \mid(A, B) \in Y_{L}\right\} \cup\left\{i_{L}, o_{L}\right\}$

Dalam process discovery peneliti menggunakan sebuah algoritma alpha, adalah algoritma yang paling mudah

DOI: https://doi.org/10.29207/resti.v6i1.3732

Lisensi: Creative Commons Attribution 4.0 International (CC BY 4.0) 
Menyambungkan place yang tersedia dengan input dan $Y_{w}=\left\{(A, B) \mid\left((A, B) \in X_{W} \vee P_{(A, B)} \in P_{\left.W^{-L 1 L}\right) \wedge}\right.\right.$ output yang ada

$F_{L}=\left\{\left(a, P_{(A, B)}\right) \mid(A, B) \in Y_{L} \wedge a \in A\right\} \cup$ $\forall_{\left(A^{\prime}, B^{\prime}\right) \in} X_{W} \vee P_{\left(A^{\prime}, B^{\prime}\right)} \in P_{W^{-L 1 L}}\left(A \subseteq A^{\prime} \wedge B \subseteq\right.$ $\left\{\left(P_{(A, B)}, b\right) \mid(A, B) \in Y_{L} \wedge b \in B\right\} \cup\left\{\left(i_{L}, t\right) \mid t \in T_{I}\right\} \cup$ $\left.\left.B^{\prime} \Rightarrow(A, B)=\left(A^{\prime}, B^{\prime}\right)\right)\right\}$

\section{$\left\{\left(t, O_{L}\right) \mid t \in T_{O}\right\}$}

Penggambaran ulang workflow net

$\alpha(L)=\left(P_{L}, T_{L}, F_{L}\right)$
Selanjutnya merupakan pendefinisian algoritma

(7) dan termasuk dalam $Z_{W}$ alpha++ sebagai berikut [16]:

Places yang menghubungkan transisi length one loop diidentifikasi dan termasuk dalam $L_{W}$

$X_{W}=\left\{(A, B, C) \mid A \subseteq T^{\prime} \wedge B \subseteq T^{\prime} L 1 L \wedge\right.$

$\forall_{a \in A} \forall_{c \in C}(a>W c \wedge \neg(c \Delta W A)) \wedge \forall_{b \in B} \forall_{c \in C}(c>$ $\left.W b \wedge \neg\left(c \Delta_{W} b\right)\right) \wedge \forall_{a \in A} \forall_{b \in B} a \nVdash W b \wedge$

$\left.\forall \forall_{a 1, a 2 \in A} a_{1} \# W a_{2} \wedge \forall_{b 1, b 2 \in} B b_{1} \# W b_{2}\right\}$

$L_{W}=\left\{(A, B, C) \in X_{W} \mid \forall\left(A^{\prime}, B^{\prime}, C^{\prime}\right) \in X_{W} A \subseteq \mathrm{A}^{\prime} \wedge B \subseteq\right.$

$\left.\mathrm{B}^{\prime} \wedge \mathrm{C} \subseteq \mathrm{C}^{\prime} \Rightarrow(A, B, C)=\left(A^{\prime}, B^{\prime} . C^{\prime}\right)\right\}$

Semua transisi length one loop dihapus dari input log dan kemudian diproses menggunakan algoritma alpha

$W^{-L 1 L}=\varnothing$

For each $\sigma \in W$ do:

(a) $\sigma^{\prime}=\sigma$

(b) For each $t \in L 1 L$ do: i. $\sigma^{\prime}:=$ eliminate Task $\left(\sigma^{\prime}, t\right)$

(c) $W^{-L 1 L}:=W^{-L 1 L} \cup \sigma^{\prime}$

Semua urutan implicit relation terdeteksi

$\left(P_{W}-{ }^{L 1 L}, T_{W}-{ }^{L 1 L}, F_{W}{ }^{L 1 L}\right)=a\left(W-{ }^{L 1 L}\right)$

Algoritma alpha menemukan WF-net berdasarkan $W^{-L I L}$ dan menguhubungkan urutan tersebut $P_{W}=P_{W}-{ }^{L 1 L}, T_{W}=T_{W}-{ }^{L 1 L} \cup L 1 L, F_{W}=$
$F_{W}-{ }^{L 1 L} \cup F_{L 1 L}$

Melakukan eliminasi pada implicit yang terjadi dalam langkah

Treat each $a \mapsto_{W^{1}} b \in I D_{W^{1}}$ as $a \rightarrow$

$W b$ and $I D_{W^{2}}=\left\{(a, b) \mid a \in T^{\prime} \wedge b \in T^{\prime} \wedge\right.$

$\left.a \longmapsto_{W^{2}} b\right\}$

$I D_{W^{2}}:=$ eliminateRDByRule1 $\left(I D_{W^{2}}\right)$

$X_{W}=\left\{\left(A \cup A_{2}, B \cup B_{2}\right) \mid P_{W-L 1 L} \wedge A_{2} \cup B_{2} \neq \varnothing \wedge\right.$ $A \cap A_{2}=\emptyset \wedge B \cap B_{2}=\emptyset \wedge \forall_{A \in} A \forall_{B \in} B_{2}(a \mapsto$ $\left.W_{1} b \vee a \mapsto W_{2} b\right) \wedge \forall_{a \in A_{2}} \forall_{b \in} B \cup B_{2}\left(a \mapsto_{W^{1}} b \vee\right.$ $\left.a \mapsto_{W^{2}} b\right) \wedge \forall_{a_{2} \in} A \forall a^{2} \in A_{2}\left(a_{2} \#_{W} a_{1} \wedge a_{2} \gg\right.$ $\left.W a_{1}\right) \wedge \forall_{b 1 \in} B \forall_{b 2 \in} B_{2}\left(b_{1} \#_{W} b_{2} \wedge b_{1} \gg W b_{2}\right.$
Treat each $a \mapsto_{W^{2}} b \in I D_{W^{2}}$ as $a \rightarrow$
$W b$ and $I D_{W^{3}}=\left\{(a, b) \mid a \in T^{\prime} \wedge b \in T^{\prime} a \mapsto\right.$
$\left.I D_{W^{3}} b\right\}$

Pada rumus ini diterapkan untuk mengurangi implicit dependensi yang berlebihan pada $I D_{W}{ }^{3}$

$I D_{W^{3}}:=$ eliminateRDByRule $2\left(I D_{W^{3}}\right)$

Semua places yang melibatkan implicit dependensi diturunkan berdasarkan relasi $\mapsto_{W}^{3}$

$X_{W=\left\{(A, B) \mid A \subseteq T^{\prime} \wedge B \subseteq T^{\prime} \wedge\right.}$

$\forall_{a \in A} \forall_{b \in B} a \mapsto W^{3} b \wedge \forall_{a 1, a 2 \in A} a_{1} \#_{W} a_{2} \wedge$

$\forall_{b 1, b 2 \in B} b_{1} \#_{W} b_{2}$

$Z_{W}=\left\{(A, B) \in X_{W} \mid \forall_{\left(A^{\prime}, B^{\prime}\right) \in} X_{W} A \subseteq A^{\prime} \wedge B \subseteq B^{\prime} \Rightarrow\right.$ $\left.(A, B)=\left(A^{\prime}, B^{\prime}\right)\right\}$

Semua place yang melalui tahap discovery dikumpulkan lalu length one loop dan places juga ditambahkan ke WF-net

$P_{W}=\left\{P_{(A, B)} \mid(A, B) \in Y_{W} \cup Z_{W}\right\}-$

$\left\{P_{(A, B)} \mid \exists_{\left(A^{\prime}, B^{\prime}, C^{\prime}\right) \in} L_{W} A^{\prime}=A \wedge B^{\prime}=B\right\} \cup$

$\left\{P_{(A \cup C . B \cup C)} \mid(A, B, C) \in L_{W}\right.$

$T_{W}=T_{W^{-L 1 L}} \cup L 1 L$

$F_{W}=\left\{\left(a, P_{(A, B)}\right) \mid(A, B) \in P_{W} \wedge a \in A\right\} \cup$

$\left\{\left(P_{(A, B)}, b\right) \mid(A, B) \in P_{W} \wedge b \in B\right\}$

WF-net dengan non free choice dan place yang telah dihasilkan ditambahkan ke net yang ditemukan oleh algoritma alpha ++

$\alpha^{++}(W)=\left(P_{W}, T_{W}, F_{W}\right)$

\section{Hasil dan Pembahasan}

Pada penelitian ini akan menjelaskan mengenai perbandingan algoritma alpha dan alpha++ dari data pengunjung aplikasi e-commerce. Data yang akan dianalisa adalah data yang masuk, data didapatkan berdasarkan database pada aplikasi seperti yang sudah

16) disebutkan pada bagian pengumpulan data diatas. Kemudian data tersebut pada tahap awal akan dilakukan pre-processing data dan dilakukan pemberian label pada setiap aktivitas.

Dalam mengolah data untuk mendapatkan model proses yang sesuai dengan kasus pada penelitian ini yaitu, menganalisa pengunjung aplikasi e-commerce dengan menggunakan algoritma alpha dan alpha++ digunakanlah sebuah tool ProM Lite versi 1.2. 


\subsection{Pre-processing Data}

Sebelum digunakan untuk analisa, dataset akan diproses pada tahap pre-processing. Pada tahap ini data dilakukan sort by ip_address agar data tersebut lebih terurut. Setelah dilakukan tahap pre-processing, atribut yang digunakan yaitu ip_address, label, timestamp, products_id dan activity.

\begin{tabular}{|c|c|c|c|c|}
\hline ip_address & label & created_at & products_id & activity \\
\hline 69.171 .231 .112 & A & 13/10/2021 13:05 & NULL & user menuju home \\
\hline 69.171 .231 .112 & A & $13 / 10 / 202114: 48$ & NULL & user menuju home \\
\hline 69.171 .231 .112 & A & $13 / 10 / 202114: 50$ & NULL & user menuju home \\
\hline 69.171 .231 .112 & A & $13 / 10 / 2021$ 14:51 & NULL & user menuju home \\
\hline 69.171 .231 .112 & A & 13/10/2021 14:57 & NULL & user menuju home \\
\hline 69.171 .231 .112 & A & 13/10/2021 17:36 & NULL & user menuju home \\
\hline 103.119.230.243 & A & $20 / 10 / 20213: 33$ & NULL & user menuju home \\
\hline 103.119.230.243 & D & 20/10/2021 3:35 & 6 & user melihat produc \\
\hline 103.119.230.243 & D & 20/10/2021 3:35 & 2 & user melihat produc \\
\hline 103.119.230.243 & A & 20/10/2021 3:35 & NULL & user menuju home \\
\hline 103.119.230.243 & A & 20/10/2021 5:56 & NULL & user menuju home \\
\hline 103.119 .230 .243 & D & 20/10/2021 5:56 & 6 & user melihat product \\
\hline
\end{tabular}

Gambar 3. Pre-processing Dataset

\subsection{Analisis Data}

Hal pertama yang dilakukan yaitu melakukan import file dengan format CSV kemudian diubah menjadi format file XES (eXtensible Event Stream) yang merupakan format standar yang digunakan oleh sebagian besar tool proses mining [17]. Ditunjukan pada Gambar 4.

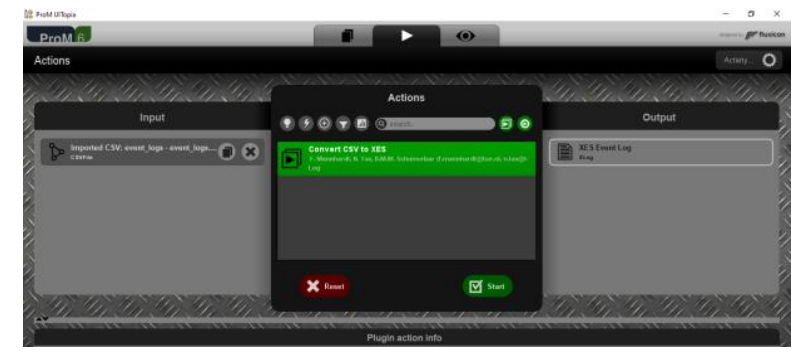

Gambar 4. Import File

Setelah melakukan import data, hal yang perlu dilakukan selanjutnya adalah menentukan case column yaitu ip_address dan event column yaitu label.

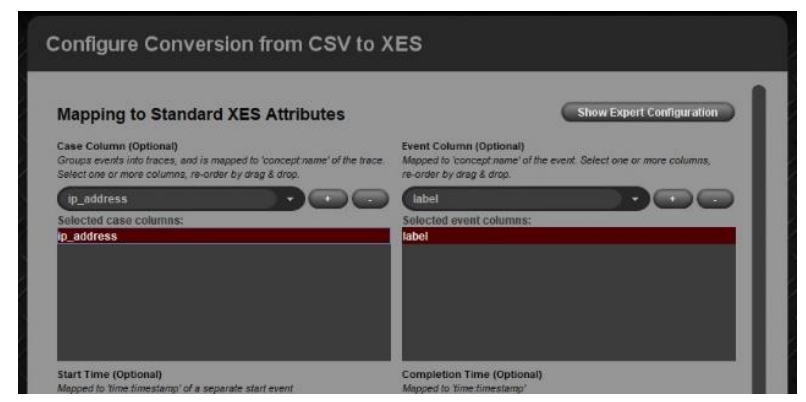

Gambar 5. Mapping to Standard XES Attributes

Pada penelitian ini column yang digunakan adalah ip_address sebagai caseID karena pada penggunaannya users_id tidak dapat terdeteksi jika default nilainya 0 di mana nilai tersebut terlihat di saat user tidak melakukan login dan register. Maka dari itu ip_address menjadi caseID untuk dapat menangkap aktivitas pengunjung aplikasi e-commerce.

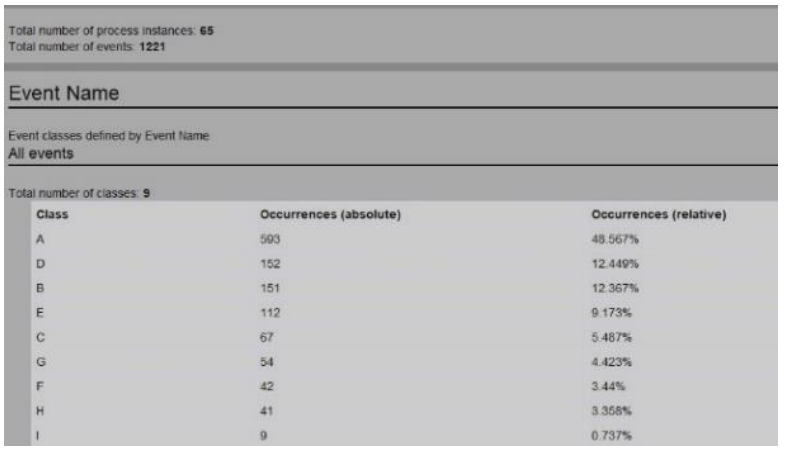

Gambar 6. Log Summary Activity

Selanjutnya log summary menampilkan detail seluruh kejadian dari event log berdasarkan class yang ada dan mengurutkannya dari class terbanyak hingga terkecil. Dalam penelitian ini class terbanyak yaitu A (User menuju home) dan class terkecil yaitu I (User menghapus product).

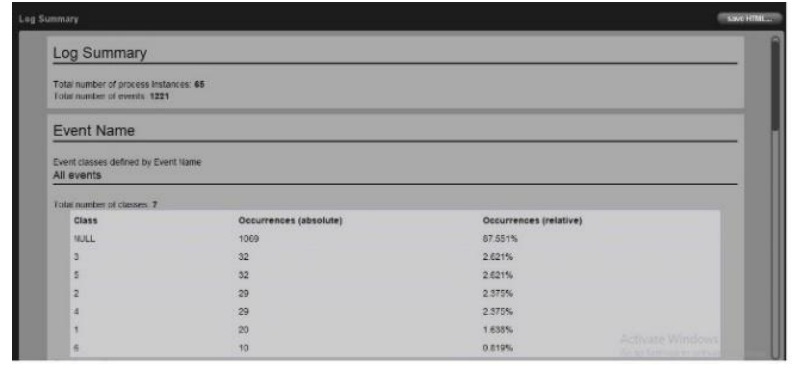

Gambar 7. Log Summary Products_id

Terlihat pada Gambar 7. log summary juga dapat menampilkan produk yang paling banyak dilihat oleh user, pada products_id 3 dilihat oleh 32 user, diikuti dengan products_id 2 dilihat oleh 29 user, dan produk yang paling sedikit yaitu dengan products_id 6 dilihat oleh 10 user. Hal ini berfungsi untuk melihat minat dari user terhadap produk yang terdapat pada aplikasi.

\subsection{Penerapan Algoritma Alpha}

Proses discovery dilakukan untuk menghasilkan model proses dengan menggunakan tools ProM, pada toosl tersebut telah terdapat plugin algoritma alpha miner. Seperti yang ditunjukan pada Gambar 8.

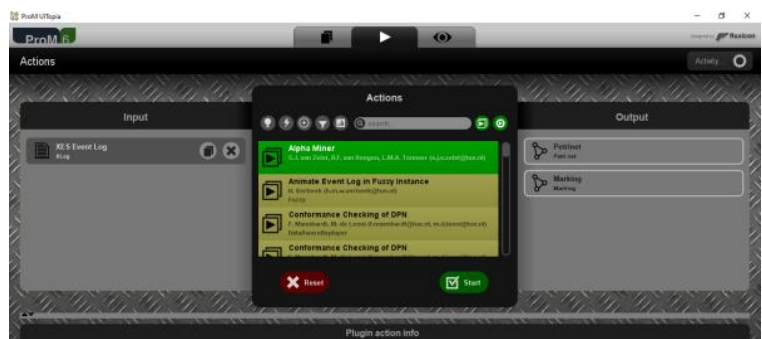

Gambar 8. Plugin Alpha Miner

Setelah dilakukan discovery menggunakan algoritma alpha akan terbentuk model proses pada Gambar 9. Terdapat sebuah shortloop pada aktivitas I dan F. Dikarenakan aktivitas yang ada pada data terdapat

DOI: https://doi.org/10.29207/resti.v6i1.3732

Lisensi: Creative Commons Attribution 4.0 International (CC BY 4.0) 
banyak aktivitas berulang yang mengakibatkan tidak belum terhubung oleh aktivitas lainnya sedangkan untuk terhubung satu sama lain. Di mana contoh length-one- aktivitas F sudah masuk ke dalam aktivitas lain. loop seperti pada aktivitas (BBADDD, BBACB). Dan length-two-loop terdapat pada aktivitas berikut (BABADFEH, CGEAEA).

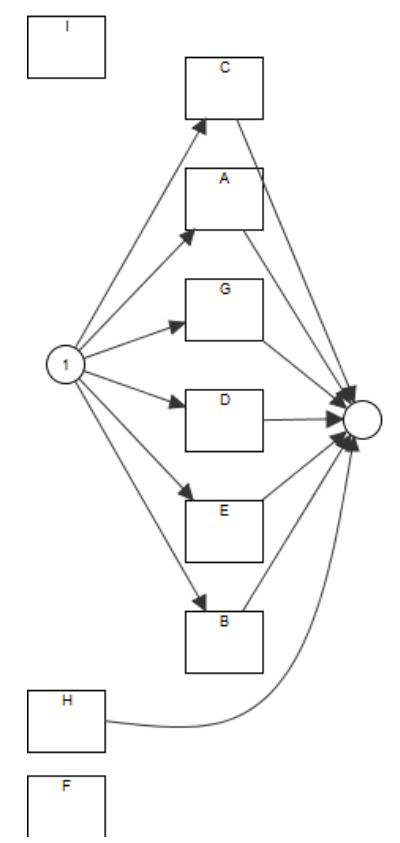

Gambar 9. Petri net Algoritma Alpha

Dari Gambar 9. disimpulkan alpha tidak bisa mengatasi sebuah shortloop [18]. Selain itu, alpha juga memiliki kekurangan (1) length one loop, merupakan sebuah aktivitas yang dieksekusi beberapa kali secara berurutan. (2) length two loop, dua buah aktivitas yang berurutan dieksekusi beberapa kali, (3) aktivitas tak terlihat, sebuah aktivitas yang tidak memiliki jejak catatan kejadian, di mana aktivitas tersebut tidak termasuk ke dalam transition serta tidak mampu menampilkan ke dalam net yang dihasilkan algoritma alpha, (4) aktivitas ganda, aktivitas dalam alur kerja yang sama terjadi lebih dari sekali, (5) Implisit place, jika sebuah lokasi dalam petri net dikatakan implisit maka keberadaannya tidak memberikan pengaruh catatan kejadian sebuah aliran kerja, dan (6) pilihan tidak bebas, di mana algoritma alpha tidak bisa menambang informasi dengan baik karena jaringan tersebut tidak bisa mendapatkan log yang benar [7].

\subsection{Penerapan Algoritma Alpha++}

Dalam algoritma alpha++ ini merupakan perbaikan dari kelemahan yang ada pada alpha. Pada Gambar 10. terdapat place yang digunakan sebagai pre-condition dan post-condition pada transisi [16]. Place juga ditambahkan melalui tahap discovery. Kemudian pada short loop dan place ditampilkan ke dalam petri nets. Algoritma alpha++ mendeteksi non-free choice dengan cara menemukan short loop. Pada alpha++ ini terdapat non-free choice pada aktivitas F dan $\mathrm{H}$. Dalam model proses yang dihasilkan terdapat aktivitas I yang masih

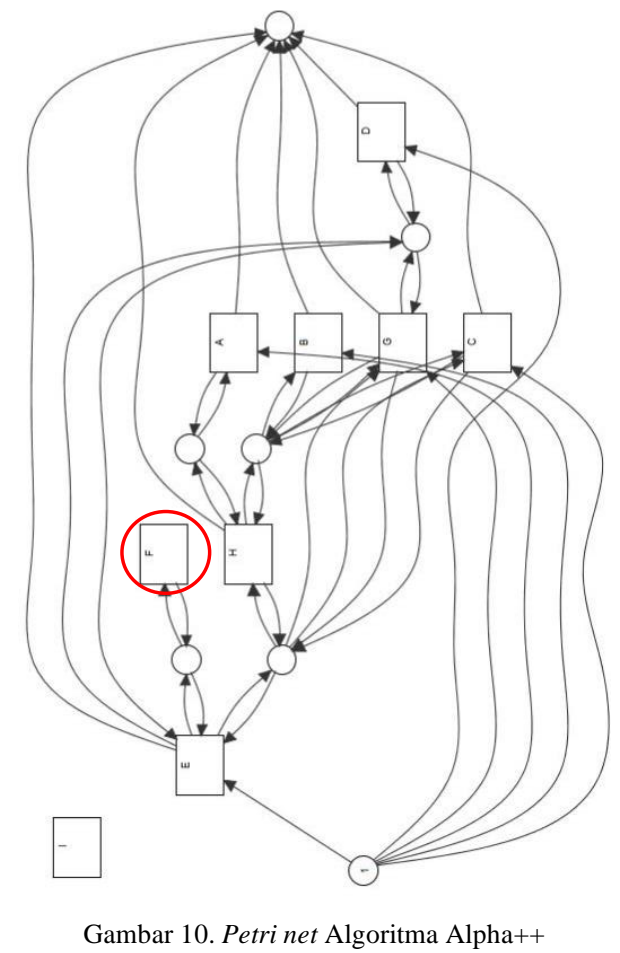

Kasus seperti ini disebabkan adanya noise pada log [19] dan incompleteness [14]. Penjelasan noise pada log merupakan suatu event log yang berisi aktivitas yang langka dan tidak sama dengan aktivitas lain. Sedangkan untuk incompleteness yaitu aktivitas yang terlalu sedikit dan mengakibatkan sedikitnya varian yang sama. Berikut contoh aktivitas pada salah satu pengunjung yang mengakibatkan aktivitas I tidak terhubung pada aktivitas lain yaitu

\section{(AADFEIEHAEADDFEAEIEIEEADAAAAADDFEI} EIEADACAAAAACGAAAABADDFEIE).

\section{Kesimpulan}

Dari hasil penelitian yang telah dilakukan dapat diketahui bahwa aplikasi e-commerce yang telah dibuat dapat menangkap sebuah event log dari pengunjung (user behavior) yang melakukan aktivitas terhadap aplikasi dan aktivitas tersebut tersimpan ke dalam database.

Terkait dengan evaluasi dua algoritma alpha dan alpha++ untuk menganalisa sebuah aktivitas pengunjung aplikasi e-commerce, pada hasil yang diperoleh pada algoritma alpha yaitu length one loop, merupakan sebuah aktivitas yang dieksekusi beberapa kali secara berurutan berdasarkan event log dari aplikasi e-commerce yang dirancang yaitu (BBADDD, BBACB) tidak dapat menghasilkan model proses. Selain itu pada length two loop, merupakan dua buah aktivitas yang berurutan dieksekusi beberapa kali yaitu pada aktivitas (BABADFEH, CGEAEA). Sedangkan untuk kelebihan

DOI: https://doi.org/10.29207/resti.v6i1.3732

Lisensi: Creative Commons Attribution 4.0 International (CC BY 4.0) 
pada algoritma alpha++ dapat mendeteksi non-free [8] choice pada aktivitas tetapi untuk aktivitas I tidak dapat membentuk model proses yaitu pada aktivitas (AADFEIEHAEADDFEAEIEIEEADAAAAADDFEI EIEADACAAAAACGAAAABADDFEIE).

Adapun saran yang dapat dipertimbangkan pada penelitian selanjutnya adalah dapat menambahkan IN dan OUT dengan tujuan agar user dapat terdeteksi pada saat masuk atau keluar aplikasi, selain itu dapat menggunakan algoritma yang bisa memperbaiki kekurangan yang ada pada algoritma alpha dan alpha++.

\section{Daftar Rujukan}

[1] A. N. Anastasia and I. Handriani, "Aplikasi Sistem Order Jasa Graphic Designer Berbasis Web Pada PT. Decorner," J. Ilm. FIFO, vol. 10, no. 1, p. 87, 2018, doi: 10.22441/fifo.v10i1.2943.

[2] S. Kosasi, "Perancangan Sistem E-commerce Untuk Memperluas Pasar Produk Oleh-Oleh Khas Pontianak," Snastia, vol. 2015, no. Oktober, pp. 110-119, 2015.

[3] B. Jokonowo, R. Sarno, S. Rochimah, and B. Priambodo, "Process mining: Measuring key performance indicator container dwell time," Indones. J. Electr. Eng. Comput. Sci., vol. 16, no. 1, pp. 401-411, 2019, doi: 10.11591/ijeecs.v16.i1.pp401-411.

[4] W. M. P. Van Der Aalst, "Process-aware information systems: Lessons to be learned from process mining," Lect. Notes Comput. Sci. (including Subser. Lect. Notes Artif. Intell. Lect. Notes Bioinformatics), vol. 5460 LNCS, no. January 2009, pp. 1-26, 2009, doi: 10.1007/978-3-642-00899-3_1.

[5] D. T. Nguyen and J. E. Jung, "Real-time event detection for online behavioral analysis of big social data," Futur. Gener. Comput. Syst., vol. 66, pp. 137-145, 2017, doi: 10.1016/j.future.2016.04.012.

[6] R. Adhim, M. A. Shiddiq, F. F. Ghizbunaza, and M. A. Yaqin, "Process Discovery pada Event log Permainan Hay Day menggunakan Algoritma Inductive Miner," Semin. Nas. Inov. dan Apl. Teknol. di Ind. 2019, no. February, pp. 66-73, 2019.

[7] D. Reißner, A. Armas-Cervantes, R. Conforti, M. Dumas, D. Fahland, and M. La Rosa, "Scalable alignment of process models and event $\log$ s: An approach based on automata and Scomponents," Inf. Syst., vol. 94, p. 101561, 2020, doi: 10.1016/j.is.2020.101561.
A. Hermawan, "Business Process Context Analysis Based on 'Event log,"' J. Penelit. dan Pengemb. Komun. dan Inform., vol. 4, no. 3, p. 122699, 2014.

[9] H. Rizqifaluthi and M. A. Yaqin, "Process mining Akademik Sekolah menggunakan RapidMiner," Matics, vol. 10, no. 2, p. 47, 2019, doi: 10.18860/mat.v10i2.5158.

[10] P. Nafasa, I. Waspada, N. Bahtiar, and A. Wibowo, "Implementation of Alpha Miner Algorithm in Process mining Application Development for Online Learning Activities Based on MOODLE Event log Data," ICICOS 2019 - 3rd Int. Conf. Informatics Comput. Sci. Accel. Informatics Comput. Res. Smarter Soc. Era Ind. 4.0, Proc., no. October, 2019, doi: 10.1109/ICICoS48119.2019.8982384.

[11] R. Sarno, K. R. Sungkono, M. Taufiqulsa'di, H. Darmawan, A. Fahmi, and K. Triyana, "Improving efficiency for discovering business processes containing invisible tasks in non-free choice," J. Big Data, vol. 8, no. 1, 2021, doi: 10.1186/s40537021-00487-X.

[12] A. K. A. De Medeiros, W. M. P. Van Der Aalst, and A. J. M. M. Weijters, "Workflow Mining: Current Status and Future Directions," Lect. Notes Comput. Sci. (including Subser. Lect. Notes Artif. Intell. Lect. Notes Bioinformatics), vol. 2888, no. i, pp. 389-406, 2003, doi: 10.1007/978-3-540-39964-3_25.

[13] Y. A. Effendi and R. Sarno, "Parallel process discovery using a new Time-Based Alpha++ Miner," IIUM Eng. J., vol. 21, no. 1, pp. 126-141, 2020, doi: 10.31436/iiumej.v21i1.1173.

[14] R. Accorsi, M. Ullrich, and W. M. P. Van Der Aalst, Process mining Data Science In Action Second Edition, vol. 35, no. 5. 2012.

[15] A. K. A. de Medeiros, B. F. van Dongen, W. M. P. van der Aalst, and A. J. M. M. Weijters, "Process mining: Extending the a algorithm to mine short loops," BETA Work. Pap. Ser., 2004.

[16] L. Wen, W. M. P. Van Der Aalst, J. Wang, and J. Sun, "Mining process models with non-free-choice constructs," Data Min. Knowl. Discov., vol. 15, no. 2, pp. 145-180, 2007, doi: 10.1007/s10618-007-0065-y.

[17] Afina Lina Nurlaili and Agung Mustika Rizki, "Analisis Kualitas Model Proses dalam Implementasi Process mining : Literature Review," J. Comput. Electron. Telecommun., vol. 1, no. 2, pp. 1-10, 2021, doi: 10.52435/complete.v1i2.74.

[18] H. W. Sun, W. Liu, L. Qi, Y. Y. Du, X. Ren, and X. Y. Liu, “A process mining algorithm to mixed multiple-concurrency shortloop structures," Inf. Sci. (Ny)., vol. 542, pp. 453-475, 2021, doi: 10.1016/j.ins.2020.07.003.

19] D. Yue, X. Wu, H. Wang, and J. Bai, "A review of process mining algorithms," BMEI 2011 - Proc. 2011 Int. Conf. Bus. Manag. Electron. Inf., vol. 5, no. 70872082, pp. 181-185, 2011, doi: 10.1109/ICBMEI.2011.5914454. 